\title{
Desafios metodológicos para a (auto)biografia de família
}

\author{
Methodological challengers for a family's (auto)biography
}

Flavia de Oliveira Barreto

Doutora em Ciências Humanas/Sociologia Professora da Faculdade de Formação de Professores da Universidade do Estado do Rio de Janeiro flaviabarreto2011@gmail.com

Resumo: $O$ artigo discute o desafio da objetividade na composição de narrativa (auto)biográfica que toma como base documento de história oral/história de vida, quando personagem e narrador pertencem a mesma família. O diálogo reflexivo se estabelece a partir de um olhar sobre a obra e o texto de Edgar Morin - "Um Ponto no Holograma A vida de Vidal, meu pai". Apresentamos algumas definições, mantendo o foco no problema da relação entre narrador e personagem pertencentes à mesma família. $\mathrm{O}$ artigo também aborda os problemas da objetividade no tratamento da subjetividade e das questões referentes ao afeto, como um dos grandes desafios metodológicos.

Palavras-chave: História oral, (auto)biografia de família, metodologia em (auto)biografia, memória.

\begin{abstract}
The article discusses the challenge of the objectivity when composing the (auto)biographic narrative based upon a document of oral history/life history when the character and narrator belong in the same family. The reflexive dialogue is established from the paper and text of Edgar Morin - "A point in the hologram. The life of Vidal my father". We introduce some definitions whilst maintaining the focus on the problem of the relationship between narrator and character who are members of the same family. The article also covers the problems of the objectivity when dealing with the subjectivity and the questions concerning the affection as one of the greatest methodological challenges.

Keywords: Oral history, family (auto)biography, (auto)biography methodology, memory.
\end{abstract}




\section{Introdução}

O chamamento a pensar os problemas metodológicos para uma biografia de personagem com quem se tem relação de família surgiu durante a composição do livro "Magnífico Sivuca maestro da sanfona" (BARRETO, 2012), sendo o personagem central percebido pela autora como um intelectual orgânico, atuante no campo cultural da arte musical internacional.

Trata-se de narrativa (auto)biográfica de família, posto que o biografado e a autora são pai e filha. Inúmeras dificuldades a respeito da organização da narrativa quanto ao lugar a ser assumido pelo narrador na passagem do texto oral para o texto escrito permitiram que fosse descortinado o imenso terreno em que vicejam os desafios para a objetividade frente ao propósito de compor "biografia" de membro da família. Para além da catarse psicanalítica ironicamente obrigatória nesses casos, muitas questões metodológicas se apresentaram. Neste texto pretendemos por meio da utilização do trabalho (auto)biográfico de Edgar Morin sobre o pai, aprofundar essas reflexões. Edgar Allan Poe (2009).

No campo das Ciências Humanas alguns debates se impõem de modo imperioso. Podemos considerar uma proposição no limite da ruptura os exercícios de abordagem da realidade social que pretendem alterar os elementos já estabelecidos como aceitáveis para pesquisa, modificando sujeitos, objetivos, objetos e meios. Isso se deve às buscas por novas ligações essenciais, imprecisas e fluidas a constituir um saber centrado na dimensão temporal da pessoa e seus ciclos de vida, em oposição ao saber objetivo sem sujeito. "As ligações essenciais, imprecisas e fluidas constituem a característica dos problemas ligados à crises paradigmáticas multiformes e em múltiplos níveis. O tratamento delas leva ao que Kuhn chama de pesquisas não ordinárias, extraordinárias...” (PINEAU, 2006: 333).

Embora apontados como possibilidade de ruptura, os estudos centrados no sujeito não devem ser tomados como uma vertente isolada, pois, ao contrário disso, entendemos não ser possível invalidar a abordagem da macro realidade e privilegiar como perspectiva de pesquisa a abordagem da micro realidade. As duas perspectivas deveriam ser consideradas como complementares porque o resultado das pesquisas realizadas

\footnotetext{
${ }^{1}$ Nada é mais detestável à sabedoria que demasiada sutileza.
} 
conforme tão distintos paradigmas podem vir a contribuir para que sejam iluminados aspectos que, tanto em uma, quanto em outra perspectiva parecem se apresentar em opacidade.

A metodologia em História Oral aponta de forma clara para a pertinência no diálogo entre o relato de vida e o contexto histórico em que se inserem. As narrativas (auto)biográficas são cada vez mais incorporadas como fontes que podem contribuir para o enriquecimento sobre a realidade social, à medida em que oferecem detalhes do cotidiano, do imaginário e da experiência vivida por indivíduos. Como Verena Alberti (2004: 26) ao citar Niethammer: "Essa história de experiência é (...) uma possibilidade de nos aproximarmos empiricamente de algo como o significado da História dentro da História." Sejam estes personagens que narram suas experiências vividas, protagonistas de eventos históricos de grande impacto, ou pessoas cujas vidas comuns parecem não ocasionar nenhum impacto na sociedade, mas que são exemplos históricos da mesma, visto que estes últimos têm sido absorvidos pela perspectiva de democratização da construção da narrativa da História.

Verena Alberti conclui, apontando para aceitação da validade do uso das autobiografias, que permitem promover, por meio da incorporação das histórias de vida como opção metodológica, a inclusão da subjetividade como elemento fundamental da constituição epistemológica do conhecimento, assimilando dialeticamente a práxis das relações entre indivíduo e sociedade, e fazendo aflorar o desafio de trabalhar fora do quadro lógico-formal positivista. "Em outros termos, a escrita biográfica poderia tornarse o lugar de um trabalho reflexivo, centrado no impacto da história da civilização na qual toma forma a história de vida pessoal" (DOMINICÉ, 2006: 356).

No campo da História, o debate sobre a autobiografia surge atravessado pela discussão da metodologia da História Oral. Nesse caso, as questões consideradas como objeto de reflexão metodológica são primordialmente, memória, narrativa, tempo e passado.

A memória quando se torna o foco do olhar na metodologia da História Oral é relato de ação, uma criação posterior ao passado, que o ordena e significa. A memória torna-se objeto no seio da reflexão sobre a teoria das fontes, que debate desse modo os problemas da tipologia da memória, dos processos de constituição da memória, dos processos de documentação da memória, e da noção de memórias em disputa. Consideremos que, enquanto recurso para pesquisa, a memória deve toda a sua importância ao fato de constituir no lugar "presente", o passado. Como conclui Verena 
Alberti sobre a contribuição da História Oral, - que se constitui nas narrativas do passado, na organização do tempo e do sentido dos fatos - "sua grande riqueza está em ser um terreno propício para o estudo da subjetividade e das representações do passado tomados como dados objetivos, capazes de incidir (de agir, portanto) sobre a realidade e sobre nosso entendimento do passado" (2004: 42).

Quer seja na dimensão individual, quer seja na dimensão social, a memória é composta por lembranças, que podem ser valorizadas ou desvalorizadas conforme os critérios de eleição do narrador ao fazer seus registros. Também compõe a memória o esquecimento de fatos e situações vividas, seja porque não são lembrados, seja porque algo os impede de vir à tona.

As possibilidades de erro e de ilusão são múltiplas e permanentes: aquelas oriundas do exterior cultural e social inibem a autonomia da mente e impedem a busca da verdade; aquelas vindas do interior, encerradas, às vezes, no seio de nossos melhores meios de conhecimento, fazem com que as mentes se equivoquem de si próprias e sobre si mesmas (MORIN, 2000: 32 -33).

Essencialmente, todo processo de acionamento e construção da memória é um esforço que se faz contra o tempo que interpõe distância entre o presente, onde se dá a narrativa do fato, e o momento de seu acontecimento. E esse esforço acontece em meio a conflitos em que fatos são rejeitados ou valorizados e interpretações são contrapostas.

Nossa mente, inconscientemente, tende a selecionar as lembranças que nos convém e a recalcar ou mesmo apagar, aquelas desfavoráveis, e cada qual pode atribuir-se um papel vantajoso. Tende a deformar as recordações por projeções ou confusões inconscientes. (...) (MORIN, 2000: 22)

A tessitura da memória social sempre foi objeto de contenda entre os interesses do Estado, instituições, movimentos e grupos sociais que disputam suas distintas visões sobre a sociedade e os rumos a serem tomados na construção do porvir. Por outro lado, a memória individual é um forte componente da memória social. Por isso, entendemos a relevância das narrativas autobiográficas como fonte legítima e de enriquecimento para historiadores na composição da memória social.

A partir das narrativas de vida confrontamos o problema das biografias e autobiografias que enquanto narrativas do eu, embora se tornem documentos a ser 
considerados como fontes passíveis de serem incorporadas pelos historiadores na construção da narrativa da História, permanecem como um produto cuja pertinência ao campo do pensamento científico está ainda postergada às brumas da arte literária, sem se constituir sequer nesse campo em um gênero bem definido.

A (auto)biografia é uma categoria complexa e instável pelo fato de ser um relato em prosa, numa escrita sobre a própria existência, centrada na vida individual e na história da personalidade, nos diz Lejeune (2008). Atento à necessidade de diferenciar a narrativa autobiográfica e os gêneros adjacentes tais como a novela biográfica, o relato de memórias, o poema autobiográfico e o diário, Lejeune busca estabelecer uma fronteira entre o fictício e o factual, por meio do pacto autobiográfico, no qual o autor precisa estar comprometido com a exatidão histórica. O objetivo de Lejeune é o de apontar um caminho para o delicado problema de tornar a narrativa autobiográfica passível de ser conceituada enquanto um gênero a ser compreendido dentro do mesmo campo da biografia.

Em busca de referências para definir o gênero, o autor aponta, entre as várias possibilidades de estruturação do texto autobiográfico, a escolha sobre a escrita do eu que pode tomar a forma em que o narrador se apresenta como distinto de si mesmo e referese a si na terceira pessoa. Mas, na sua manifestação clássica, encontramos a identidade clara entre personagem da autobiografia e narrador que se apresenta no uso da primeira pessoa. Esse seria a princípio, o marco basilar a distinguir a autobiografia da biografia. No caso da escrita de si, o narrador e o personagem biografado são a mesma pessoa, podendo se apresentar em posição autodiegética (uso da primeira pessoa na narrativa), ou apresentando-se na segunda ou terceira pessoa, mas ainda assim, havendo a coincidência entre narrador e personagem narrado.

Por conseguinte, a coincidência entre narrador e personagem narrado pode ser tomada como referencial de distinção entre autobiografia e biografia, pois, nesta última modalidade a distinção entre narrador e personagem deve aparecer como condição óbvia. Tudo o que envolve a distinção de gêneros entre autobiografia e biografia parece se resumir então à reposta para a indagação acerca da maneira pela qual se manifestam a identidade do autor ou do personagem narrador.

Ao tratar com acuidade a apresentação dos referenciais que podem ser tomados para definir e diferenciar gêneros tão aproximados como autobiografia e biografia, Philippe Lejeune, em seu texto, vem depois problematizar as definições iniciais e apresentar as condições paradoxais nas quais uma autobiografia pode ser estruturada. Um 
exemplo clarificador se encontra na situação da autobiografia publicada sobre os que não escrevem. Quer seja porque não dominam a técnica da escrita, por não serem alfabetizados, ou porque não tem a habilidade para fazer a passagem entre o texto oral e o texto escrito.

Tornou-se uma prática a contratação de ghostwriter para a elaboração de autobiografias de celebridades. Neste contexto como se colocam os autores dessas obras? Em que lugar social podem ser identificados os que escrevem biografias que são apresentadas como autobiografias? São eles colaboradores, secretários, escritores tradutores? Em muitos casos, a existência desse narrador colaborador é omitida por completo.

O contraditório em relação a estes "acontecimentos autobiográficos" se situa exatamente na passagem do texto oral para o texto escrito. Nesse ponto da ação autobiográfica assistimos esmaecer a fronteira inicialmente colocada entre biografia e autobiografia a partir do lugar e da relação entre narrador e personagem.

\section{Problemas de método quando narrador e personagem estão numa relação de família}

O caso das (auto)biografias construídas quando existe relação familiar entre narrador e escritor parece confirmar uma das mais relevantes questões de caráter metodológico, ou seja, o foco na posição a ser assumida pelo escritor como o elaborador da transição entre o texto oral e o texto escrito. Essa questão evidencia o clássico obstáculo à cientificidade nas Ciências Humanas, condensado na obrigatoriedade de se confrontar a relação paradoxal entre a objetividade e a subjetividade.

A obra de referência com o título "Um ponto no holograma. A história de Vidal, meu pai.", foi escolhida para estabelecer a reflexão em torno do problema e tem como autor Edgar Morin (2006). Constatamos que Morin dedicou grande parte de sua produção ao gênero autobiográfico e biográfico. São dele os títulos: "Diário da Califórnia", "Diário da China", “O ano sísifo", Edwige a inseparável”, "Meus demônios”, "Meu caminho", "Amor, poesia, sabedoria", "Chorar, amar, rir, compreender", "Minha Paris, minha memória", "O X da questão: o sujeito à flor da pele". Morin declara a relevância da produção de diários e outros títulos de caráter biográfico e autobiográfico ao comentar sobre uma dessas produções: "Esse diário integra minhas observações objetivas e minhas 
impressões subjetivas (o pleno emprego da objetividade) e indica o progresso, as descobertas, as incertezas, a complexidade de minha pesquisa" (MORIN, 2012:12).

Atribuo a Morin a qualificação de autor e não de escritor, ainda que o trabalho em análise se trate de obra (auto)biográfica. Isto dito, por tomar como base a premissa de Roland Barthes que identifica como auteur aquele que produz não somente as próprias obras, mas as regras de formação de outros textos, teatros de linguagem, fundamentos sobre os quais outros seguidores mais convincentes ou menos convincentes se apresentaram, se apresentam, ou ainda se apresentarão. $\mathrm{Na}$ mesma linha de argumentação, Michel Foucault (2006) identifica a categoria de autor como o fundador de um tipo de discursividade, diferenciando-o do escritor enquanto um produtor de textos particulares, cuja produção subsiste pelo reconhecimento da crítica. O presente artigo aborda, por conseguinte, a relação tensionada entre a História Oral, a memória e a ciência, atravessados pela trajetória pessoal do cientista e o registro de suas práticas ao desenvolver uma narrativa (auto)biográfica.

Evidencia-se aqui, desde já, a provocação sobre a proposta de Morin que é definida como trabalho de biografia do pai, elaborada conforme os parâmetros metodológicos do pensamento complexo, mas é referida neste texto como trabalho (auto)biográfico. Consideramos que a discussão inerente à produção de narrativas biográficas levanta a questão do envolvimento do biógrafo com o biografado e, nesse sentido, toda biografia conteria em si forte dose de autobiografia. Reforçamos que, no caso de "Um ponto no holograma", há uma relação visceral entre biógrafo e biografado, pois se trata da indissociável relação entre filho e pai que conviveram proximamente e, ao fazê-lo, tornou-se o biógrafo testemunha participante, intérprete apaixonado e parcial, que estende este olhar sobre a trajetória pessoal do pai. Carregado de indagações sensíveis e emotivas, que pretendeu ter controlado nas primícias metodológicas da biografia, Edgar Morin parece deixar escapar a complexidade que envolve o próprio trabalho.

Nesse sentido, podemos propor que seja considerada a biografia sobre alguém com quem se mantém uma relação de caráter familiar como um gênero para além das fronteiras da biografia, alcançando por hibridação o patamar de (auto)biografia.

O que motiva e justifica o uso dos parênteses é o fato de não se tratar nitidamente de biografia e sequer de autobiografia, porque nem sempre o narrador participante, no seu fazer profissional, quer ter explicitado em todos os matizes e cores o seu envolvimento com o personagem biografado, ou, mesmo que o considere enquanto um dado revelado, 
o pesquisador pode optar por tratar o vínculo afetivo familiar de maneira a pretender ter sobre o mesmo um efetivo controle.

Se o pesquisador, ao apresentar seu trabalho como biografia, estiver imbuído do propósito de manter distância, neutralidade, condução da narrativa assumindo uma postura imparcial em busca de uma narrativa "verdadeira", usará de artifícios para assim conduzir o texto. Embora se trate de opção bastante usual, podemos olhar criticamente este tipo de condução metodológica que imagina manter sob controle objetivo o envolvimento afetivo e a carga de subjetividade presentes no texto escrito por meio de recursos que, muito aquém da metodologia, se restringem a uma construção de natureza estética.

Nisso consiste o desafio proposto neste artigo: identificar os momentos em que Edgar Morin (pseudônimo de Edgar Nahoum) pretende conter Edgar Nahoum (seu nome de família), e os momentos em que Edgar Nahoum (o filho) escapa ao pesquisador, sociólogo, e emerge no texto, ainda que de modo velado a contaminar a pretendida imparcialidade, a inviabilizar a objetividade consciente. Neste trabalho de Edgar Morin o autor está movido pela ideia de que a racionalidade pode conter e controlar por uso de artifícios a emoção. A relação pai/filho não foi considerada com clareza em sua intensidade e presença, mas trata-se de um desafio não apenas para Morin, pois se estende a todos os que se dedicam ao trabalho de (auto)biografias pela reflexão exigente que se impõe.

Edgar Morin apresenta desde as primeiras páginas 'a história de Vidal' como um trabalho circunscrito ao campo teórico metodológico do pensamento complexo. O sentido emprestado ao título 'Um ponto no holograma' compreende-se no interior do pensamento complexo, sendo o foco escolhido a história de Vidal, um ponto singular do holograma, que contém ainda, em cada ponto que o compõe, a informação da totalidade em que se inscrevem todos os pontos. Para o autor a proposta não é declaradamente guiada por laço de ternura e sim pelo propósito de fazer um livro verdadeiro² ${ }^{2}$ MORIN, 2006:8).

Portanto, tratamos de um trabalho inspirado pelo firme propósito de compor uma obra norteada pela própria formação acadêmica e científica, conduzida por pressupostos metodológicos que são também explicitados de modo a confirmar o caráter objetivo da biografia de Vidal.

\footnotetext{
${ }^{2} \mathrm{O}$ grifo é meu e todos os grifos posteriores nas citações de Morin serão da mesma forma.
} 
Para dimensionar a grandeza do desafio que é ser parte do campo e ao mesmo tempo cartógrafo deste, Morin se apresenta consciente do desafio, como hábil controlador do mal estar desafiador, como controlador das negociações entre o eu e o texto, garantindo-se pela disciplina do tratamento de si mesmo na terceira pessoa.

Vidal é o objeto e o tema deste livro, que tenta dar nova vida a sua vida. Por ser ele o verdadeiro tema do livro, não quis parasitá-lo utilizando o "eu" do narrador como testemunha. Quando intervenho inevitavelmente como filho, falo de mim na terceira pessoa, a fim de objetivar a mim mesmo, e conservo o seu "eu" em todas as passagens aqui presentes de sua autobiografia oral. Sendo ele o objeto deste livro, quero evocá-lo com o máximo de objetividade: nomeio-o na terceira pessoa e, como desejo me situar o mais próximo possível, designo-o por seu primeiro nome, Vidal (MORIN, 2006: 8).

As fontes declaradas por Morin são: o relato oral autobiográfico gravado por Véronique Grappe-Nahoum, filha de Morin e neta de Vidal, pesquisadora da EHESS (Escola de Estudos Avançados de Ciências Sociais), utilizando o relato bruto ora aberto, ora encoberto, transcrito em itálico; arquivos pessoais de Vidal; diário de prisão e demais documentos pessoais, familiares e profissionais; O livro Histoire dês Israélites de Salonique em seus sete volumes; e outras obras e artigos sobre os judeu-espanhóis. Percebemos a atenção com o rigor metodológico, impregnado da substancialidade factual, como recurso que embala o pleito pela imparcialidade objetiva da narrativa.

Voltando o olhar para o debate acerca dos problemas metodológicos da etnografia, é relevante resgatar a contribuição de Malinowski, formatador do conceito de observação participante, que é destacado por Geertz: "não apenas estive lá, como fui um deles e falo com sua voz" (Geertz, 2009: 37), ao citar Malinowski e afirmar que o que ocorre não é apenas a observação participante, mas também estamos diante da escrita da testemunha participante. Obviamente, a contribuição de Malinowski não é incorporada por Edgar Morin que, por sua vez, parece não se aperceber do problema que lhe atravessa a narrativa.

Fica evidente a negação da força da relação entre filho e pai, que surge desde o preâmbulo da narrativa "disciplinada", pela proposta de tratamento na terceira pessoa, destinado a este filho, mais do que uma testemunha participante, é também sujeito da vida familiar de Vidal. 
Morin se utiliza da ideia da imparcialidade alcançada por meio do autocontrole que lhe permitiria estabelecer desejados níveis de "verdade objetiva" e, por conseguinte, endossa a corriqueira percepção do leitor em relação ao narrador, da qual nos diz Walter Benjamin: Por mais familiar que seja seu nome, o narrador não está de fato entre nós, em sua atualidade viva. Ele é algo de distante, e que se distancia ainda mais. (BENJAMIN, 1987: 197). Assume ao lugar do narrador onisciente, presença oculta e não nominada na narrativa, portanto sabidamente investido de autoridade, e o máximo que admite quanto à proximidade que pretende em relação ao pai deve aparecer na opção retórica de tratá-lo pelo nome, Vidal.

A opção do autor pela narrativa com o uso do narrador oniscinete reforça a autoridade do autor como profissional pesquisador a estruturar a narrativa a partir de sua lógica objetiva. Todavia, a distância que separa o autor do "outro", objeto da narrativa, pretensamente mantida com rigor é, entretanto, artificialmente mantida. $\mathrm{O}$ artifício implementado não é recurso exclusivo de Edgar Morin, que parece não dimensionar estar tensionado pela sua existência como Edgar Nahoum, o filho, pois a mesma questão também é encontrada na produção etnográfica. E sobre o tema, Geertz aponta a tendência entre os pesquisadores, em uma espécie de movimento em defesa da objetividade científica, para que se mantenha o problema no campo da névoa, para a garantia da objetividade científica. "A dificuldade está em que a estranheza de construir textos ostensivamente científicos a partir de experiências em grande parte biográficas, que é o caso do que fazem os etnógrafos, afinal, fica inteiramente obscurecida" (GEERTZ, 2009: 22).

Seguro da aplicabilidade de sua epistemologia pessoal, Morin, o autor, possuidor da autoridade de pensador, intelectual provido de instrumental metodológico, na introdução de seu livro, está se declarando capaz de aprisionar Edgar Nahoum, filho de Vidal Nahoum, para que este não contamine com sua subjetividade e interpretação emotiva a narrativa biográfica que pretende marcar com a chancela de verdadeira.

Morin contradiz Morin para fazer calar Nahoum.

As possibilidades de erro e de ilusão são múltiplas e permanentes: aquelas oriundas do exterior cultural e social inibem a autonomia da mente e impedem a busca da verdade; aquelas vindas do interior, encerradas, às vezes, no seio de nossos melhores meios de conhecimento, fazem com que as mentes se equivoquem de si próprias e sobre si mesmas (MORIN, 2000: 32,33). 
A um olhar mais atento, que não se deixa cooptar credulamente pela lógica discursiva do discurso cientificista, a proposição de Morin evidenciada nos primeiros parágrafos instiga o leitor a acompanhar curioso como se dará no decorrer da narrativa o controle que Edgar Morin pretende estabelecer sobre Edgar Nahoum filho, no texto em que o primeiro pretende escrever sobre o pai, sabedores que somos, de que um e outro, são a mesma pessoa.

O motivo pelo qual consideramos mais adequado, no caso das narrativas biográficas de família, a classificação das mesmas como (auto)biografias está fundada na questão de que no modelo biográfico se separa o narrador, colocado na posição profissional de pesquisador, como possibilidade de que esteja garantida a construção de um saber objetivo porque enquanto o sujeito de biografia fornece a informação, o profissional aplica sobre ela o tratamento objetivo.

Se assumimos o sentido (auto)biográfico emprestado às narrativas biográficas em que existem laços de família, optamos pelo modelo dialógico de co-construção de sentido, quando o sentido da narrativa não fica reduzido à consciência e ordenação da memória acionada pelo personagem narrador, nem à análise do pesquisador. Essa proposta se ampara no fato de que ambos, autor da narrativa oral e tradutor dessa narrativa para o texto escrito são coadjuvantes nos fatos e experiências de vida tendo sido ambos igualmente afetados pelos eventos sucedidos no passado compartilhado.

\section{Como e quando Edgar Nahoum o filho escapa de Edgar Morin o pesquisador}

No transcorrer dos primeiros capítulos de "O ponto no holograma" Edgar Morin cumpre seu propósito de "objetividade" e discorre sobre a história dos judeus 'sefarditas'3, que estiveram instalados por mil e quinhentos anos nos territórios que, em 1492, se tornam a Espanha de Isabel de Castela e Fernão de Aragão. O decreto desses soberanos obriga os judeus à conversão ou ao exílio, no prazo final de agosto de 1492, o que leva os antepassados dos Nahoum se transferirem para outras terras. Muitos encontram refúgio na cidade portuária inicialmente de nome Tessalonica, às margens do mar Egeu. Conquistados e invadidos por godos, hunos, avaros, búlgaros e árabes, normandos da Sicília, cruzados e venezianos, finalmente a Salonica se torna parte da

\footnotetext{
${ }^{3}$ Sefarditas - judeus originários de comunidade judaica da Espanha.
} 
Turquia no início do século XVI, embora tenha se mantido como um microcosmo da Espanha, onde a língua judaica corrente permanece o castelhano do século XV. Os judeus da sefarad espanhola se mantêm como maioria da população Salonica até os anos de 1912

A vida de Vidal é perpassada pela grande Guerra de 1914-1918, e o momento do aparecimento do filho Edgar é a porta que se abre para o início de sua participação na narrativa (auto)biográfica e 'objetiva'.

São alguns episódios marcantes, nos quais as emoções e a subjetividade transbordam para o texto, para além do controle e da impessoalidade, posto que o autor continua a destinar a si mesmo o tratamento na terceira pessoa. Ainda que Edgar seja 'ele', suas emoções aparecem a estabelecer doses claras de subjetividade, julgamentos, sentimentos e ressentimentos, dúvidas e referências etnocêntricas.

\section{A morte da mãe}

Vidal acreditava haver poupado o filho ao não lhe anunciar, no ato, a morte da mãe, e ao excluí-lo das cerimônias do luto e do enterro. Sem dúvida, tudo teria sido diferente se a criança houvesse podido, junto com o pai, compartilhar a dor, chorar no momento do enterro, abraçar a avó Beressi que tanto amava Luna. Mas, ao contrário, o silêncio e a dissimulação acerca dessa morte provocaram o silêncio e dissimulação da criança, e foi no próprio seio da família que ele se achou exilado, perdido. Muito mais tarde, quase trinta anos depois, quando Edgar evocar a morte da mãe num livro publicado em 1959, Vidal e Corinne compreenderão que ele amava a mãe (MORIN, 2006: 184).

Vidal é muito carinhoso e paciente com o filho, que, apesar do mal entendido fundamental e do rancor secreto contra o pai, sente por ele menos impulsos de afeto. [Vidal pensa que o filho é indiferente à morte da mãe e Edgar pensa que o pai traiu a mãe]. (MORIN, 2006: 192).

Ele ainda não compreendeu e nunca compreenderá que o pior é impedir alguém de participar do adeus à pessoa querida, e que as lágrimas e o pranto de dor são necessários (MORIN, 2006: 318).

É evidente que o material utilizado para a composição das passagens selecionadas não deve ter sido o depoimento de Vidal. Estamos frente à narrativa direta da testemunha 
participante, o filho, embora isso não esteja devidamente assinalado. Se o rancor era secreto, se havia dissimulação dos sentimentos, e o pai nunca mudou o próprio procedimento frente às situações de morte, fica evidenciado que a narrativa somente poderia ter como origem a vivência do filho, sendo por conseguinte, uma narrativa (auto)biográfica.

A maneira pela qual o pai de Edgar lidou com a morte da mãe parece ter criado um sério problema na relação entre pai e filho. As passagens transcritas do texto nos permitem entrever que a questão perdurou por décadas. Pela tentativa de proteger o filho de um forte e terrível sentimento de perda, o pai passou a ser punido e incompreendido em sua intenção primordial.

Aqui não há imparcialidade e o 'ele', ainda que permaneça como o tratamento disciplinado aplicado ao filho, este não está ausente, pois prevalece a interpretação dele sobre a opção de Vidal. Não há uma reflexão para aplicar olhar de distanciamento ou uma tentativa de compreensão/relativização da 'culpa' do pai.

Ao contrário, ele é apresentado como alguém incapaz de reconhecer seu erro ao lidar com situação da morte de parente próximo, da mesma forma que anteriormente, e disso novamente é culpado. "Não compreendeu e nunca compreenderá". Um olhar distanciado e imparcial poderia ter colocado os personagens envolvidos na situação do enfrentamento da morte em outra perspectiva, numa narrativa mais amena.

Nesta etapa, sem dúvida, a biografia de Vidal torna-se a (auto)biografia de Vidal compartilhada pelo filho, pesquisador, sujeito da narrativa e narrador participante. Edgar Morin começa a permitir que a objetividade de seu texto sucumba ante a emoção de Edgar Nahoum, que até então havia se mantido disciplinadamente calado.

\section{A passagem da adolescência para a vida adulta}

Se considerarmos os postulados iniciais assumidos pelo autor da narrativa, quando afirma que a principal fonte documental é o relato oral autobiográfico gravado por Véronique Grappe-Nahoum, filha de Morin e neta de Vidal, "um relato bruto utilizado ora aberto, ora encoberto e transcrito para o livro em itálico”, a leitura do seguinte parágrafo acende o estranhamento: "Vidal não percebe que, desde os quinze anos, o rapaz quer sair um pouco de sua tutela, viver a própria vida” (MORIN, 2006: 194). 
Se Vidal não percebe o que pretende o filho, quem percebe então? Novamente a discrepância entre a expectativa de um e a ação do outro é o tema de que se ocupa o autor do texto. Agora nos fala o filho interpretando a ação do pai conforme seu ângulo de visão. Quanto a isso não há dúvida.

O filho descreve as táticas utilizadas pelo pai para mantê-lo sob seu domínio, e estabelece um juízo de valor que também delimita os campos de diferença e estranheza entre os dois. Conforme o autor, um se orienta pelo ethos oriental e o outro é pertencente à cultura e ethos ocidental, sedimenta-se entre ambos o estranhamento, mas não por esse motivo, e sim claramente nascido de um acontecimento que gerou ressentimentos do filho pelo pai.

Ademais, a situação e a tática descrita como recorrente na relação Vidal/filho não é exclusiva de uma cultura 'oriental', porque encontramos narrativas similares na literatura e na cinematografia quando se apresentam conflitos no interior de famílias de origem latina, como italianas, sul-americanas, espanholas, entre outras. "A estratégia de Vidal é uma estratégia astuciosa de oriental. Primeiro desviar-se, esperar, entorpecer, e depois, no momento certo, anunciar o parricídio, "Se você quer matar o seu pai...", e simular a agonia" (MORIN, 2006: 195)

Com a participação de Edgar Nahoum na Resistência francesa durante a Segunda Guerra, o narrador demarca o momento em que, por fim, o filho rompe com a dominação paterna a lhe solicitar que seja razoável e não coloque em risco a própria vida. "Vidal ficará estarrecido com a recusa (do filho abandonar a Resistência francesa) e esquecerá de morrer. Assim ruirá a autoridade absoluta da parentela, à qual ele (o filho) se submetera durante toda a vida" (MORIN, 2006: 196)

Reafirma o ressentimento em relação ao pai ao afirmar que o pai “(...) obteve tudo que queria do filho, até os vinte anos deste, por meio de chantagem e obstinação. A preocupação de proteger a vida do filho impediu o filho de viver" (MORIN, 2006: 413).

Esquece-se, todavia, de que não há exercício de poder sem a aquiescência do dominado, em especial no tocante às relações pessoais. Se fatores externos a essa relação pai/filho estivessem atuando no sentido de perpetuar a submissão do filho ao pai, o autor que se ocupa com perspectiva de abordagem do pensamento complexo, nesta passagem do próprio texto deixou de lado a visão de conjunto. Consideramos que o pensamento ou paradigma da complexidade pressupõe aspectos racionais e não racionais articulados dialogicamente, sistemicamente, holograficamente, mas que precisam estar considerados, 
explicitados, pensados e analisados. Para questionar Morin em seu exercício (auto)biográfico, citemos o próprio Morin:

Existe um problema capital, sempre ignorado, que é o da necessidade de promover o conhecimento capaz de apreender problemas globais e fundamentais para neles inserir os conhecimentos parciais e locais. (...) É preciso ensinar os métodos que permitam estabelecer as relações mútuas e as influências recíprocas entre as partes e o todo em um mundo complexo (MORIN, 2006: 14).

Restringiu-se o autor ao foco da questão em si, perdendo de vista a visão do contexto e a oportunidade de perceber em si mesmo a necessária reflexão acerca de suas opções pessoais na própria trajetória de vida.

A maneira pela qual Vidal é percebido pelo filho atribui ao pai a exclusiva responsabilidade pelas opções filiais, que no contexto da relação familiar foram feitas por um jovem, não tão jovem, na medida em que o momento da ruptura e da insubordinação ao pai somente vai se realizar aos vinte anos. Ou seja, algo emocional e afetivo os conectava e impregnava o filho de reticências quanto à possibilidade de se rebelar abertamente contra o assédio feito pelo pai, que lhe solicitava maior cuidado com a própria vida. Porém, ele já se colocava em risco desde o momento em que optou por fazer parte da resistência francesa contra a invasão alemã, antes de completar os vinte anos de idade, e o fez de maneira a ocultar essa opção do pai, durante a Segunda Guerra Mundial.

\section{O filho julga a conduta e as opções do pai}

Assim em cada eleição, Vidal vai felicitar Paul Reynaud, sem contudo votar nele. O que há de oriental nessa atitude é a preocupação de ser bem visto pelo poderoso, pelo chefe, pelo potentado.

Vidal acredita que a ameaça é menor na legalidade do que na fuga (...) Acredita, por um reflexo oriental, que o poder demonstraria reconhecimento diante de sua submissão (MORIN, 2006: 254).

Vidal atravessou a Segunda Guerra Mundial como um peixe que passa entre as malhas de uma rede (...) (MORIN, 2006: 287). 
Assim, mesmo que desejasse evidentemente a derrota do nazismo, não compreendia por que o filho corria um risco inútil e se lançava na guerra ao invés de evitá-la (MORIN, 2006: 287).

Sentia de maneira visceralmente oriental, em virtude de uma antiga sabedoria, que os judeus deviam se proteger da política e não se lançar nela, e que na luta contra o anti-semitismo arriscava-se mais a atiçar a ira persecutória do que desenraizar a ideia nefasta. (...) camuflou-se totalmente e esperou o fim da Peste (MORIN, 2006: 291).

Fica evidente que Edgar, o filho, se posiciona a partir de um olhar contundente e crítico em relação à conduta do pai, visto que este buscou durante a Segunda Guerra Mundial se colocar fora do alcance das garras do invasor alemão, sem que, todavia, assumisse a identidade judaica. Ao contrário do que fez o filho, para quem a identidade judaica é clara no interior do conflito, em especial por estar engajado na Resistência.

Também digno de nota é o fato de que a esse olhar crítico se adiciona a referência da origem 'oriental' (Turquia) do pai, o que se contrapõe de modo imediato ao posicionamento 'ocidental'(França) do filho. O sentido disso pode incluir desde a origem turca da família Nahoum, - que na figura de Vidal, luta durante toda a vida pela inserção e aceitação na sociedade francesa, problema que não atinge tão fortemente a Morin que mudou inclusive o sobrenome -, até a questão da origem judaica que não foi assimilada como referência religiosa por Vidal.

A questão judaica no contexto da Segunda Guerra, em consequência da perseguição anti-semita, se apresenta como fator claro de conflito social para os Nahoum e, evidentemente, também para Edgar, que assim como o pai não celebrava os ritos da religiosidade judaica, mas era consciente de que sua origem o tornava alvo de perseguição anti-semita.

O olhar crítico do filho parece também se estender sobre outros campos de atividade do pai, contaminando de ressentimento filial a análise que o filho e não o autor, lhe dedica.

Vidal é bom comerciante porque é hábil, mas ruim, porque não é competente (MORIN, 2006: 294).

Vidal permanece poeticamente infantil. Assim, ao chegar um dia à pequena propriedade que Corinne comprou em Vaux-sur-Seine, em 1954, ouve um 
gorjeio e, encantado, exclama: "Ouça, querida, um passarinho cantando para lhe dar bom dia" (MORIN, 2006: 298).

O filho não se contém e estende um olhar depreciativo às atitudes e percepções de Vidal sobre a vida. Citemos novamente Morin para que as dificuldades que apontamos ganhem tonalidade mais contrastante:

A compreensão mútua entre os seres humanos, quer próximos, quer estranhos, é daqui para a frente vital para que as relações humanas saiam de seu estado bárbaro de incompreensão (MORIN, 2006: 17).

Nossa mente, inconscientemente, tende a selecionar as lembranças que nos convém e a recalcar ou mesmo apagar, aquelas desfavoráveis, e cada qual pode atribuir-se um papel vantajoso. Tende a deformar as recordações por projeções ou confusões inconscientes (...) (MORIN, 2006: 22).

No próprio texto sobre a vida do pai, Edgar Morin permite que a contradição daquilo que afirma Edgar Nahoum transpareça, e adiciona um depoimento, o qual acentua o paradoxo que produz na obra de Morin os ressentimentos de Edgar o filho. Contradizem-lhe os sentidos, claramente, o olhar da jovem Danielle Angel uma prima distante, sobre Vidal: "Tão pouco cartesiano, dava a impressão de haver compreendido tudo, tinha um conhecimento agudo das coisas... e havia conservado uma imensa capacidade de maravilhar-se. Que entusiasmo! Muitas vezes me senti envelhecida ao lado dele" (MORIN, 2006: 371).

Mas, o filho não desaparece e persegue Vidal em busca de motivos para the confirmar a origem e justeza de tais ressentimentos, mantendo-se sempre desconfiado quanto ao compromisso e correção do pai frente à mãe. Questão esta, que permanece e se manifesta com claro apelo psicanalítico. “

Edgar eventualmente indagava sobre o passado, perguntava-lhe se havia tido uma amante antes da morte de sua mãe. Vidal jurava que não, mas o filho sabia que ele era um oriental, isto é, um mestre na arte de fingir sinceridade, e não ficava nem um pouco convencido (MORIN, 2006:361).

Não supera, portanto, o momento traumático ocasionado pela morte da mãe, quando o pai pensando em proteger o filho de fortes sentimentos de dor não lhe participa 
com clareza o falecimento da mãe. Assinala o autor que, como filho, não retribui mais ao pai sentimentos de afeto, a partir do dito episódio. E é essa ruptura afetiva que se estende por toda a narrativa (auto)biográfica de Morin sobre Vidal.

O mesmo sentimento fica patente na descrição que destila irritação sobre o comportamento peculiar do pai, no que diz respeito à fome, posto que este passou por fortes privações na Primeira e na Segunda Guerra Mundial. "Assim que o prato chega, seu rosto se debruça sobre ele, come vorazmente como se passasse fome, com a concentração absoluta de um animal" (MORIN, 2006: 365).

Edgar Morin deixa de assumir nesse trecho de seu trabalho (auto)biográfico o caráter trágico dos eventos com os quais Vidal se confrontou, perdendo de vista a relação entre a conduta individual e subjetiva e os acontecimentos históricos que envolveram de forma contundente a vida pessoal de Vidal.

\section{A identidade cultural e familiar de Edgar Nahoum transpira valores no discurso de Edgar Morin}

Há um olhar dividido e aplicado por Edgar Morin que ele carrega consigo, de modo indivisível, Edgar Nahoum e a origem judaica da família. Marcadamente ao se referir aos 'gentios', grupo social composto por todos aqueles que se unificam no contexto do Estado-Nação, cujo surgimento permitiu a invenção da Europa dos tempos modernos. Ou seja, todos os integrantes dos outros povos não judaicos.

(...) Verónique, filha do casamento gentio de Edgar (MORIN, 2006:424).

Edgar teve três casamentos gentios, Edgard teve um, do qual nasceram três filhos que vivem no mundo dos gentios (MORIN, 2006: 425).

(...) Sua primeira filha, Édith, teve um casamento gentio, a segunda casou-se com um Veil, (não gentio?) separou-se e adotou uma filha entre os gentios. Os dois filhos, Alex e Roger, entraram também no mundo dos gentios (MORIN, 2006: 425).

As filhas de Edgar também se casaram com gentios (MORIN, 2006: 426).

A utilização do termo 'gentios', da maneira pela qual é aplicada no texto, assinala de modo indiscutível a fronteira do olhar que estabelece quem está dentro e quem está fora da comunidade judaica, e o motivo. No caso, Edgar Nahoum está dentro, sempre 
esteve, embora Edgar Morin se pretenda étnica e cientificamente fora de limites e fronteiras, participante da globalização e da consequente dissolução das identidades nacionais, religando sem preconceitos os saberes, estabelecendo pontes entre as disciplinas separadas, superando distanciamentos, preconceitos e sugerindo novas unidades. Independente do aspecto religioso, pois não é este o caso na trajetória de Morin e de seu pai, tratamos do pertencimento a um grupo bem definido quanto as fronteiras que demarcam sua etnicidade.

O autor do pensamento complexo percebe, na sua vida familiar, que há os que vivem dentro (do mundo judaico) e os que vivem fora (no mundo dos gentios), entre os gentios... Esta percepção etnocêntrica constata e sedimenta distinções, antes de afirmar interligações entre "os vários mundos”, que dividem e separam, por exemplo, os homens e as mulheres, para além da questão de gênero, ainda quando pertencem a uma mesma sociedade, como no caso a sociedade francesa.

\section{Para concluir as reflexões apresentadas}

Ao lançar um olhar sobre a obra "Um ponto no holograma" como um conjunto, destacamos alguns aspectos através dos quais nos damos conta da visão do autor sobre as possibilidades biográficas.

O primeiro aspecto a salientar é a opção feita pela ordenada sequência de continuidade cronológica, como um dos recursos para dar sentido, conforme uma teoria da História no sentido de relato histórico. O que nos remete a compreensão de que para Edgar Morin, na busca pela composição de um "livro verdadeiro", ele se conduz pela noção de senso comum segundo a qual nos diz Bourdieu,

(...) a vida constitui um todo, um conjunto coerente e orientado, que pode e deve ser apreendido como expressão unitária de uma "intenção" subjetiva e objetiva, de um projeto (...) Vida organizada como uma história que transcorre, segundo uma ordem cronológica que também é uma ordem lógica, desde um começo, uma origem, no duplo sentido de ponto de partida, até seu término, que também é um objetivo (2006:184).

Uma das ilusões que acometem os biógrafos, conforme o olhar crítico de Bourdieu, que cita Allain Robes-Grillet para problematizar a questão: (...) o real é 
descontínuo, formado de elementos justapostos sem razão, todos eles únicos e tanto mais difíceis de serem apreendidos porque surgem de modo incessantemente imprevisto, fora de propósito, aleatório (GRILLET, 1984: 208 Apud BOURDIEU, 2006: 208).

Quanto ao objetivo de compor um 'livro verdadeiro', ele parece nos indicar o propósito de criar uma obra de reverência a Vidal Nahoum. Essa reverência não pode ser compreendida apenas como uma pretensão restrita a quem escreve, mas este, o narrador, pretende envolver o leitor que é o receptor da obra neste movimento de reverência. Origina-se então, do impacto causado pela leitura, a concretização da reverência ao biografado, posto que se deseja que o biografado permaneça vivo na memória daqueles que tomam contato com a obra, que registra as passagens narradas sobre aquela vida. Provém de Walter Benjamin o alerta para possibilitar a perpetuação da obra no gosto do leitor: "Nada facilita mais a memorização das narrativas que aquela sóbria concisão que as salva da análise psicológica" (1987: 204).

Ainda no tocante ao propósito do termo 'livro verdadeiro' torna-se imprescindível problematizar a noção de verdade que se introduz pelo autor, posto que a verdade, enquanto um conceito sempre relativo e referenciado a quem a proclama, onde se busca atribuir a si, indivíduo ou coletividade, a autoridade de proferir afirmações 'verdadeiras' ou 'oficiais', ambos os atributos costumeiros e próprios do senso comum, que espera encontrá-los, em especial no que diz respeito às produções biográficas.

Não se trata de libertar a verdade de todo sistema de poder - o que seria quimérico na medida em que a própria verdade é poder - mas de desvincular o poder da verdade das formas de hegemonia (sociais, econômicas, culturais) no interior das quais ela funciona no momento (FOUCAULT, 1984:11).

Finalmente, chegamos ao propósito essencial do artigo, que se coloca muito além da crítica esmiuçada de "Um ponto no Holograma", pois pretende, na verdade, que se amplie o coro dos que convocam maiores esforços no campo das metodologias voltadas para o conjunto das Ciências Humanas:

A maior necessidade (...) nas Ciências Sociais hoje, é de uma metodologia mais refinada, tão objetiva e desapaixonada quanto possível, na qual, embora os pressupostos decorrentes do condicionamento e do interesse pessoal do investigador influenciem seus resultados, esse viés seja conscientemente enfrentado, a possibilidade de outros pressupostos iniciais seja reconhecida e 
as implicações de cada um deles sejam levadas em conta no decorrer da análise (FIRTH, 1998: 488 Apud GEERTZ, 2009: 26).

Discutimos o problema metodológico da subjetividade e da objetividade no uso da História de Vida/História Oral e (auto)biografia, e concluímos ser este um tema atual e com atributo de permanente.

Embora a sequência de citações de Morin no trabalho (auto)biográfico sobre o pai, possa levar ao entendimento de que se construiu um olhar de antagonismo em relação ao autor, exatamente o contrário acontece. Somente a partir da leitura do conjunto de obras de caráter autobiográfico, tecido por Morin, é que durante a leitura de "Um ponto no holograma" sobreveio à percepção sobre a relevância em se pensar mais detidamente sobre as questões que se apresentam àqueles que se dedicam ao projeto de tecer biografias sobre personagens com os quais estabelecem laços familiares. Um desafio significativo aos pesquisadores que se dedicam ao campo atravessado por tais complexas questões. Do mesmo modo que foi difícil o enfrentamento da tensão e a negociação entre a subjetividade individual e a objetividade científica para Edgar Morin, autor de reconhecida obra sobre o pensamento complexo e suas abordagens metodológicas, havemos de perceber que assim o é para todos os demais. Um verdadeiro desafio ao pensar complexo, onde a complexidade do real vivido mantém-se impossível de ser abarcado pela racionalidade, desafia a racionalidade em todas as suas manifestações, que não são completas, mas que ao contrário, são dissimuladas pelo próprio pensamento que busca captá-la por meio de interpretações e afirmações com sentidos lineares, organizados e sistêmicos. É o próprio autor aquele a quem convidamos a confirmar tal percepção:

A verdadeira racionalidade, aberta por natureza, dialoga com o real que lhe resiste. Opera o ir e vir incessante entre a instância lógica e a instância empírica; é o fruto do debate argumentado das idéias e não a propriedade de um sistema de ideias. $\mathrm{O}$ racionalismo que ignora os seres, a subjetividade, a afetividade e a vida é irracional (MORIN, 2000: 23).

Entendemos como fundamental ter como base para as análises acerca das questões sobre as quais nos debruçamos, além das teorias sociais que nos norteiam, os fatores que influenciam essas análises, por mediação dos quais o olhar e a interpretação das realidades sociais se apresentam como processo de negociação entre observação/interpretação e 
texto, subjetividade/sensibilidade/emoção, enquanto presenças influentes que não podem ser desconsideradas na proposição da objetividade científica e na construção das teorias sobre o social.

Devemos compreender que, na busca da verdade, as atividades autoobservadoras devem ser inseparáveis das atividades observadoras, as autocríticas, inseparáveis das críticas, os processos reflexivos, inseparáveis dos processos de objetivação (MORIN, 2000: 31).

Mesmo que se tenha clareza quanto a impossibilidade da neutralidade científica no estudo das realidades sociais, reafirmamos que os pesquisadores não são neutros e que a neutralidade imparcial e objetiva é uma balela, porque o juízo de valor se apresenta à frente das interpretações, análises e conclusões. Para além dos interesses econômicos e da luta de classes, se apresentam também os interesses e olhares permeados pelas referencias culturais, os olhares advindos da subjetividade, da emoção, dos valores sociais, os contextos, os lugares de onde os sujeitos se encontram ao desenvolver suas análises, entre outros vetores a entrelaçar as pesquisas e os olhares dos pesquisadores do social.

A racionalidade deve conhecer a parte de afeto, de amor e de arrependimento. A verdadeira racionalidade sabe que a mente humana não poderia ser onisciente, que a realidade comporta mistério. Negocia com a irracionalidade, o obscuro, o irracionalizável. É não só crítica, mas autocrítica (MORIN, 2000: 23).

A preocupação com o desafio metodológico é foco constante a atravessar todas as ciências. Edgar Morin nos incita ao desafio:

O conhecimento científico é um conhecimento que não se conhece. Essa ciência, que desenvolveu metodologias tão surpreendentes e hábeis para apreender todos os objetos a ela externos, não dispõe de nenhum método para se conhecer e se pensar (MORIN, 2005: 20).

Essa observação do próprio Morin contém os problemas de objetividade debatidos nesse artigo sobre a (auto)biografia de Vidal. Tantos paradoxos entre teoria e prática 
reiteram a relevância e atualidade do problema aqui abordado. A contribuição contida no presente artigo tem o fito de somar esforços para o aprofundamento e reflexão sobre o tema, reforçando o coro dos que apostam no relato de vida como uma expressão do vivido pelo desdobramento narrativo e como afirma Gaston Pineau: "nós podemos esperar nos próprios decênios, uma mudança de mentalidades, maior tolerância, um reconhecimento do interesse e da dignidade do ato autobiográfico" (PINEAU, 2006: 249).

\section{Fontes}

MORIN, Edga. (2006). Um ponto no holograma. A história de Vidal, meu pai. São Paulo: A Girafa. (2000). Os sete saberes necessários à educação do futuro. Brasília: UNESCO. São Paulo: Cortez. (2005). Ciência com consciência. Rio de Janeiro: Bertrand Brasil. (2012). Diário da Califórnia. São Paulo: Edições SESC.

\section{Referências Bibliográficas}

ALBERTI, Verena. (2004). Ouvir contar textos em história oral. Rio de Janeiro: FGV. (2005). Manual de história oral. Rio de Janeiro: FGV.

BARTHES, Roland. (1988). O rumor da língua. São Paulo: Brasiliense.

BARRETO, Flavia de Oliveira. Magnifico Sivuca maestro da sanfona. Rio de Janeiro: ABOVE, 2012.

BENJAMIN, Walter. (1987). Magia e técnica, arte e política Ensaios sobre literatura e história da cultura. São Paulo: Brasiliense.

BOURDIEU, Pierre. (2006). A Ilusão Biográfica. In: FERREIRA, Marieta de Moraes (Org.). Usos e abusos da história oral. Rio de Janeiro: FGV.

DOMINICÉ, Pierre (2006). A formação de adultos confrontada pelo imperativo biográfico. Revista Educação e Pesquisa, São Paulo, vol. 32, n. 2, maio/ago.

FOUCAULT, Michel. O que é um autor? (2006 [1969]) In: Ditos e Escritos - Estética: literatura e pintura; música e cinema. Rio de Janeiro: Forense Universitária. (2006 [1993]). Verdade e subjetividade (Howinson Lectures). Revista de Comunicação e Linguagem, Lisboa, n. 9, pp. 203-223. (1984). Microfísica do poder. Rio de Janeiro: Graal.

GEERTZ, Clifford (2009). Obras e vidas. O antropólogo como autor. Rio de Janeiro: Editora UFRJ.

LEJEUNE, Philippe. El pacto autobiográfico y otros estudios. Madrid: Megazul Endymon, 1994.

NORONHA, Jovita Maria Gerheim (Org.) (2008). O pacto autobiográfico de Rousseau à internet Philippe Lejeune. Belo Horizonte: Editora UFMG.

POE, Edgar Allan (2009). A Carta Roubada e outras histórias de crime e mistério. São Paulo: LPM Pocket. 
PINEAU, Gaston (2006). As histórias de vida em formação: gênese de uma corrente de pesquisa-ação-formação existencial. Revista Educação e Pesquisa, São Paulo, vol. 32, n. 2, pp. 329-343, maio/ago.

Artigo recebido em 15 de outubro de 2017.

Aprovado em 20 de novembro de 2017.

DOI: 10.12957/intellectus.2017.31653 